able evidence that such have actually existed. An ingenious suggestion made by one of the party during this present visit that alkaline salts, washed out of decaying vegetation, may have brought about the change in the flint is open to the objection that no trace of this intense alteration has been detected in other outliers and outcrops of the pebble-beds equally covered by vegetation.

Although the cause of this complete alteration remains in doubt it may safely be stated that the change is due to solution, that it occurred in the pebble-beds and not on the surface of the ground, i.e., that the pebbles were not whitened on the ground surface and afterwards washed down into a pipe; that it is a process of partial de-silicification of ordinary flint.

\title{
REFERENCES.
}

I9o8. Chandler, R. H. and Leach, A. L.-“"Excursion to Knockmill (Oaklands), and Cotman's Ash." Proc. Geol. Assoc., vol. $\mathrm{xx}$, p. 532 and plate $\mathrm{xxix}$.

1909. Chandler, R. H. and Leach, A. L.- " Excursion to Otford and the Darent Valley." Proc. Geol. Assoc., vol. xxi., p. 236.

\section{EXCURSION TO WENDOVER AND BUCKLAND COMMON, NEAR CHOLESBURY.}

\section{Saturday, JUly 24TH, I920.}

Report by George Barrow, F.G.S. and J. F. N. Green, B.A., F.G.S., Directors of the Excursion.

LEAVING Wendover at I2 o'clock a start was at once made for the gravel pit, situated in the flat at the base of the gap in the Chiltern Hills, near Wendover. This flat is the northern termination of the Valley Gravel of the Misbourne valley. Southward of these pits this gravel lies at the bottom of the valley; but northward it forms the crest of a rather steep slope, the former continuation of the valley in this direction having been entirely obliterated by denudation. The base of the gravel at its termination is 500 feet above sea-level. The gravel is formed of unworr or little worn flints from the Upper Chalk, set in a matrix of sandy clay in the upper part and chalky clay in the lower. At the base of this flint-gravel is a very thin layer of small pebbles, the majority of which are of well rounded white quartz; lydite is fairly common, while very small rounded nodules of ironstone, or sand cemented into minute balls by iron-oxide, are met with in small numbers. This association clearly shows that they have been derived from the Lower Greensand northward of the Chalk escarpment, and the Directors believed their deposition to be of early Pliocene age.

Boddington Hill was then ascended; this is the south-west 
termination of the higher Chalk hills to the east of Wendover. On the crest of the hill, more than 800 feet above sea-level, the Upper Chalk is capped by Clay-with-flints, which was exposed to a depth of six feet, both in the pipe-courses and in the reservoir that has been recently made here; but unluckily these had been filled in shortly before this visit of the Association. There is no trace of any pebbles or hard material other than completely unworn flint.

The route continued along the crest of the hill till a point was reached from which the form and great size of the coombe or corrie in the Chalk hills could be well seen. This coombe is nearly 300 feet deep, a little over a mile wide, yet not much over two miles long ; indeed, as a well-marked corrie, it is hardly more than a mile long. It thus forms one of the outstanding features of this area of very old denudation; it is totally unlike the postglacial side-valleys of the Misbourne, which occur further south, for these are long and narrow. Its formation by any stream seemed impossible, and the Directors thought that much of the material could only have been removed by marine action. In any case its form and great size shows it to be in the main of tar pre-glacial age; and it was almost certainly formed when all the ground, now appreciably less than 500 teet above sealevel, was still covered by the sea, though this was probably shallow.

Continuing in a south-easterly direction towards Buckland Common, a considerable breadth of Clay-with-flints was crossed, in which no pebbles were present; but a few Tertiary pebbles. were met with before Buckland was reached. Near the village the Directors pointed out several old workings in the Brickearth, the one now in use being on the north side of the road, a little east of the meeting of four roads ; its position is thus easily fixed on the one-inch map. The pit first examined was a new excavation of almost square section and nearly 30 feet deep; three of the sides being nearly vertical. The fourth was rather more sloping and in one corner at its base, the bottom of the pit rose steeply. The manager explained that this was due to uprise in this corner of the clay full of flints, below which was the Chalk. The material that was being excavated was a reddish yellow or reddish very sandy clay; so sandy in fact that the party was surprised that bricks could be made of it. After this a slightly older, but much longer pit was visited. There is considerable variation in this At the end first examined the dominant component is a sand of variable colour, some layers being quite white. The sand has been examined by Mr. MacDonald Davies, who considers it of Eocene character. In it the bedding is horizontal except near the edge of the pit, where a fairly high dip is visible. The manager explained that this dip corresponded roughly with the uprise of the flints in clay, and if 
the latter was penetrated they soon came to Chalk. A little further east, on the north side, more yellowish and rather coarser sand occurs, which close to the edge of the pit has a high dip and contains bands or thin layers of Tertiary pebbles and a little broken flint; small pebbles of white quartz are rare. The dip and pebbles do not seem to extend far from the edge of the pit ;indeed, s.o far as could be ascertained, the bedding, where visible, was for the most part nearly horizontal. Further along, a more distinctly clay deposit occurs, and this is practically stoneless. Much of the material away from the pit-edges is so like the Reading Beds, that if one did not know the details of these beds in this area, the deposit might almost be taken for Reading Beds let down into a great solution hollow in the Chalk. But quite in the middle of the pit further along is a fairly large and extensive mass of clay containing abundant small - Tertiary pebbles, often much worn and discoloured, the whole being totally unlike any Reading Beds in situ. This material extends to the east end or the pit, and a few yards further on is another, but much smaller and shallower pit, the west side of which is also composed of the same clay with Tertiary pebbles. The evidence is thus clear that this clay is continuous beneath the undisturbed ground from one pit to another. The manager explained that the ground was not opened because there was no "brickearth" there. This is true; but in defanlt of the good exposures, it might easily be supposed that the hollow filled with these varying deposits ceased at the end of the main pit; in reality the infilled hollows are continuous from one pit to another.

In several places in the mair pit, the Brickearth has been completely removed and this shows that the sides are always formed of "Clay-with-flints"; the flints are often large and nore show any sign of rounding; they are often much broken, but sharply, and slean edges are left. Quite close to its base the deposit has the usual dark colour, but higher up it is often purplish, and in a number of cases has the deep red tint of the typical Reading Marl that over a very wide area occurs at the top of the Reading Beds ; it has clearly been derived trom the Reading Beds, the greater part of which must have still been in place not far from these hollows.

The manager stated that exactly the same clay-with-flints occurred below the brickearth even in the middle of the pits, and it becomes clear that in these hollows the Chalk surface is everywhere covered by "clay-with-flints," in tact this material lines both the sides and base of all these hollows containing the Brickearth that has been worked at so many localities on the surrounding area.

That these hollows are solution-hollows in the Chalk is clear, especially at the large pit examined, for at one point the bollow is divided into two parts, with the Clay-with-flints rising up 
sharply between. The base in the central parts of the pit is extremely uneven, and the manager stated that in some cases these deposits descend to a depth of nearly 50 feet before the Clay-with-flints is reached.

The Directors then explained that the pits visited were simply a few of a considerable series that had been worked in the immediate neighbourhood; they were arranged ofter "en echelon," suggesting that solution was going on along parallel lines or possibly master joints. Their discontinuity was possibly explained, for the most part, by the phenomenon of the clay with many Reading pebbles des ribed above ; the hollows where arranged in line, are really continuous or largely so; but the workable deposits in them are not ; hence the breaks between the pits.

The infilling appears to be in the main of pre-glacial age, and conclusive evidence of this is found wher these solution hollows are examined at appreciably lower levels, where unmistakable glacial deposits are met with. The hollows, one might almost say "subsidence channels," in which the Brickearth is. found, differ fundamentally from the pipes in the Chalk, that are also lined with clay-with-flints. These may be described as essentially circular tapering holes in the Chalk descending often to considerable depth; some are known to descend at least 50 feet; but their maximum dimension is vertical (downwards) ; the maximum dimension of the hollows containing the "brickearth" is horizontal or nearly so. The difference turns mainly on water-level; when the elongated solution-hollows at Buckland Common were formed the water-level could not have been far down, and this is why the solution is horizontal in maximum dimension. Now the water-level at Buckland would be at least 200 feet down, and surface water descends at first for the most part vertically. For practical purposes one may say that nearly 200 feet of chalk has been removed from the main valleys since the Brickearth subsidence-hollows were initiated; this deepening of the valleys has followed a more or less continuous elevation of the whole district.

There are some special features about the edges of the top of the main pit at Buckland. Locally some iron-pan occurs, and at one point there is a thin deposit containing a fair number of small pebbles of white quartz, which are rare, both in the pitdeposits and in the immediately surrounding area. Further, over much of the east end the edges of the pits are capped by a more or less bedded deposit of clay, totally unlike anything within the main pit, and clearly newer and independent of the main pit. Nothing has so far been found in it to indicate its age.

Before leaving the pits the Directors briefly noted one important point in connection with them, which may here be more fully stated. On the published Geological one-inch map 
of this area, Sheet 7 , west half, the whole of the material overlying the Clay-with-flints is called Brickearth and showr by a distinctive colour. This is misleading; the true brickearth really occurs in solution-hollows as described above, and these hollows may involve both the Clay-with-flints and the overlying wide-spread material which has been described as the "Claywith-Reading-pebbles."

The Brickearth has in reality no necessary connection with the material surrounding it and its composition does not necessarily vary with that material, whether Clay-with-flints or Clay-with-Reading-pebbles.

Mr. Green then led the party to Swain Bottom, where a series of old grassed workings was seen in a field, illustrating the streamlike form of the worked-out pits. They then walked to Lee, where a large mass of Sarsen, weighing perhaps Io tons, had been mounted on a brick pedestal near the church. It contained a few scattered pebbles, and the surface had in places a glazed appearance. Several masses of sarsen and puddingstone were piled together on the village green.

Tea was taken at Lee and the party afterwards walked to Great Missenden Station, keeping on the high ground as long as possible.

En route the Directors pointed out the curious fact that the bulk of the area they were traversing was drained by branches of the Chess, and not by the Misbourne, though the main valley of the latter, which was close by, was much wider and deeper than that of the Chess. No branch of this reached the Chalk escarpment, and there were no "wind-gaps" at the head of it or any of its branches. The gap at the head of the Misbourne was formed before the country, as a whole, was sufficiently elevated for the Chess to start its course ; but though the latter was much newer its numerous branches had eaten their way back quite close to the main valley of the Misbourne.

\section{REFERENCES.}

Geological Survey Map, Old Series, Sheet 7 .

Ordnance Survey Map, New Series, Sheet 238.

1889.-W. Whitaker, Geology of London, vol; i., pp. 281-290, Mem. Geol. Survey. 